\title{
A Case of Severe Heat Stroke With Abnormal Cardiac Findings
}

\author{
Shu WAKInO, ${ }^{1}$ MD, Shingo HorI, ${ }^{1} \mathrm{MD}$, Takuya MiMURA, ${ }^{1} \mathrm{MD}$, \\ Satoru MIYATAKE, ${ }^{1} \mathrm{MD}$, Seitaroh FuJISHIMA, ${ }^{1} \mathrm{MD}$, and Naoki AIKAWA, ${ }^{1} \mathrm{MD}$
}

\begin{abstract}
SUMMARY
We document serial changes in the electrocardiogram (ECG) and myocardial markers in a case of severe heat stroke treated with cooling procedures. A 23-year-old comatose male with heat stroke was presented in the emergency room. The condition of the patient was complicated by hepatic failure, rhabdomyolysis, acute renal failure, and cardiac abnormalities. ECG revealed diffuse ST-T elevation; serum levels of myocardial markers were remarkably high and diffuse hypokinesis was observed on the echocardiogram. Cooling procedures, including applying cold vapor to the patient's skin, a gastric lavage with cold water, and an intravenous cold fluid infusion were not successful. Since multiple organ damage (heart, liver, central nervous system, and kidney) was evident, we utilized continuous hemodialysis and hemofiltration, using cold dialysate for efficient cooling. The patient recovered from the multiple organ damage and was removed from the intensive care unit 14 days after the onset. The cardiac abnormalities had normalized within several days without any damage to the myocardium. Q waves were not detected in any lead in the ECG. When interpreting ST-T elevation in the ECG of a heat stroke patient, caution should be used so as to not misdiagnose it as an acute myocardial infarction. (Int Heart J 2005; 46: 543-550)
\end{abstract}

Key words: Heat stroke, Electrocardiography, Multiple organ failure, Myocardium

HEAT stroke is an acute thermoregulatory failure that often results from exposure to high temperatures. ${ }^{1)}$ The diagnosis of heat stroke is usually based on central nervous system dysfunction and a rectal temperature of $41^{\circ} \mathrm{C}$ or higher, as well as occasional multi-organ damage and dysfunction. ${ }^{2,3)}$ Heat stroke can be exercise induced (exertional) or non-exercise induced (classic), and occurs when heat gain exceeds heat loss from the skin by radiation, convection, or evaporation. $^{4)}$

Several cardiac complications have been documented in heat stroke cases, ${ }^{5,6)}$ and certain nonspecific ECG changes, including ST-T elevation, have been described. ST-T elevation is rare in heat stroke and is sometimes attributed to cor-

From the ${ }^{1}$ Department of Emergency Medicine, School of Medicine, Keio University, Tokyo, Japan.

Address for correspondence: Shu Wakino, MD, Department of Internal Medicine, Keio University, 35-Shinanomachi, Shinjuku-ku, Tokyo 160-8582, Japan.

Received for publication October 7, 2004

Revised and accepted January 7, 2005. 
onary artery lesions. ${ }^{7)}$ Echocardiographic findings and myocardial marker levels in heat stroke have also been reported. ${ }^{8)}$ However, to the best of our knowledge, there have not been any reports concerning serial changes in ECG and myocardial marker levels after successful cooling.

In this paper, we report our observations on one patient with heat stroke who showed severe cardiac dysfunction. The ECG finding was diffuse ST-T elevation, which resembles that of acute myocardial infarction (AMI), although the affected leads in the ECG were unrelated to the territory of the coronary artery. The echocardiogram showed diffuse abnormal wall motion and no regional hypokinesis, which ruled out a diagnosis of AMI. The serum levels of myocardial markers were remarkably elevated. We continuously measured the ECG and serum myocardial markers, which detected a complete reversal of these abnormalities within a week. Q waves were not detected in any lead in the ECG. This case is unique because severe cardiac damage by heat stroke with ST elevation was reversed completely with aggressive cooling therapy and the serial changes in the ECG and serum cardiac specific markers were documented.

\section{Case Report}

A 23-year-old male construction worker was transferred to our emergency department because of loss of consciousness on July 5, 2003. He had been in a closed workplace on the $6^{\text {th }}$ floor of a building under construction. The ambient temperature was $28.1^{\circ} \mathrm{C}$, the humidity was $53 \%$, and the wind velocity was $3.6 \mathrm{~m} /$ $\mathrm{sec}$ at that time in the area. He started work at 9:00 am, and fainted abruptly at noon; he was first sent to a nearby clinic. Without any reason, he refused to receive intravenous fluid supplementation and quickly left the clinic. He was later found lying on the street, and was transferred to our hospital at 1:15 pm.

On arrival, the patient was in a coma and the GCS scale was E1V1M2. Although his arterial pulse was palpable, his blood pressure was not measurable. His respiration rate was $32 / \mathrm{min}$ and the pulse was 156 beats/minute, which was regular. Core temperature measured inside the urinary bladder was $42.1^{\circ} \mathrm{C}$. Physical examination revealed a sluggish bilateral light reflex, a dry tongue, skin without any sweat, a normal heart beat without a murmur or gallop, a normal respiratory sound, and a mildly distended abdomen. The ECG revealed ST elevation in leads I, II, III, aVL, aVF, and $\mathrm{V}_{3-6}$, and a tall $\mathrm{T}$ wave in $\mathrm{V}_{1-2}$ (Figure 1A). The echocardiogram showed diffuse hypokinesis with a $40 \%$ ejection fraction. A cardiologist commented that severe hypokinesis was evident in the apex of the left ventricle. A chest X-ray was normal and his brain CT scan did not detect anything harmful. The color of his urine was dark brown and the urinalysis results were marked "myoglobulinuria and proteinuria with granular casts". Hematuria 


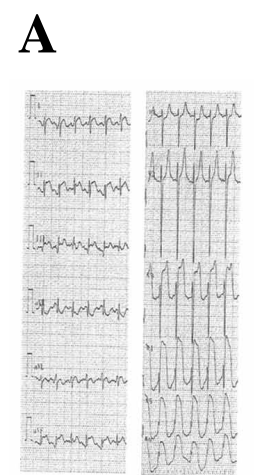

Day 1

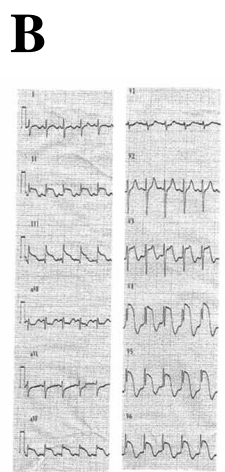

Day 2
C

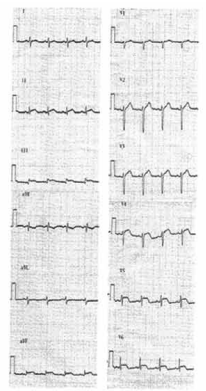

Day 4
D

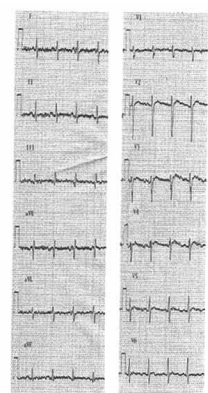

Day 7

Figure 1. Serial changes in ECG findings in severe heat stroke.

ECG was measured when the patient was transferred to the emergency room (A). ST elevation in I, II, III, aVL, aVF, and $\mathrm{V}_{3-6}$, and a tall $\mathrm{T}$ wave in $\mathrm{V}_{1-2}$ were observed, and still remained on day 2 (B). On day 4 , these changes began to be normalized $(\mathbf{C})$ and were completely normalized on day 7 (D).

was not detected. The hemoglobin value was $16.7 \mathrm{~g} / \mathrm{dL}$ and the hematocrit was $49.5 \%$. The white blood cell count was $21,800 / \mathrm{mm}^{3}$ and the platelet count was $261,000 / \mathrm{mm}^{3}$. The blood chemistry test results indicated that total protein was $10.1 \mathrm{~g} / \mathrm{dL}$; total bilirubin, $0.8 \mathrm{mg} / \mathrm{dL}$; blood urea nitrogen, $20.3 \mathrm{mg} / \mathrm{dL}$; creatinine, $3.7 \mathrm{mg} / \mathrm{dL}$; and uric acid, $32.4 \mathrm{mg} / \mathrm{dL}$. The sodium value was $149.6 \mathrm{mmol} /$ $\mathrm{L}$; potassium value, $6.2 \mathrm{mmol} / \mathrm{L}$, calcium value, $5.5 \mathrm{mg} / \mathrm{dL}$, and phosphorus value, $6.7 \mathrm{mg} / \mathrm{dL}$. Lactate dehydrogenase was $704 \mathrm{IU} / \mathrm{L}$; aspartate serine transferase, $125 \mathrm{IU} / \mathrm{L}$; and aspartate lactate transferase, $127 \mathrm{IU} / \mathrm{L}$. The level of creatine phosphokinase (CPK) was 1,337 IU/L. Blood gas analysis showed metabolic acidosis with an increased anion gap.

After a diagnosis of heat stroke with renal and hepatic dysfunction, 2 liters of ice-cooled saline were infused intravenously. Cold water was applied to the skin, which was also fanned. Gastric lavage was undertaken using 2 liters of iced saline, although the core temperature remained above $40^{\circ} \mathrm{C}$. Because the systolic blood pressure was becoming lower than $60 \mathrm{mmHg}$, intravenous administration of dopamine was started to maintain the blood pressure. The patient was intubated and admitted to the intensive care unit.

The patient was then covered with cold blankets and extracorporeal circulation was started using cold dialysate at $36^{\circ} \mathrm{C}$ to reduce his internal temperature. Two hours after beginning the extracorporeal circulation, his body temperature decreased to $38.4^{\circ} \mathrm{C}$, blood pressure rose to $120 / 60 \mathrm{mmHg}$, and the light reflexes of the bilateral pupils were restored to normal and prompt. His urine color 
became darker and urination ceased. The second blood chemical test at 4:00 pm revealed the elevation of serum creatinine $(4.7 \mathrm{mg} / \mathrm{dL})$ and CPK $(40,900 \mathrm{IU} / \mathrm{L})$.

Because rhabdomyolysis was suspected, continuous hemodialysis and hemofiltration (CHDF) were started in the evening of the admission day (day 1). This was done in order to preserve intrinsic renal function and to remove myoglobin, uric acid, and other unknown substances that were considered to impair the level of consciousness or renal function. Since the second day, his body temperature had remained under $38.5^{\circ} \mathrm{C}$, and the serum potassium level was within the normal limit by virtue of the cold blanket and CHDF. However, on day 2, the serum levels of CPK had peaked at 337,700 IU/L, and the patient entered a state of disseminated intravascular coagulation (DIC) with thrombocytopenia, a prolonged prothrombin time, and a decreased level of fibrinogen. Thrombocyte transfusion and intravenous administration of gabexate mesilate, a serine proteinase inhibitor, were started and continued for 3 days.

ECGs were performed and myocardial specific markers were continuously measured in order to follow cardiac dysfunction. The tall $\mathrm{T}$ wave disappeared on day 2; although the ST elevation observed on day 1 still remained (Figure 1B), it began to return to normal on day 4 (Figure 1C). On day 7, the ECG returned to a completely normal state (Figure 1D). The myocardial specific markers, MB-isoform of creatinine phosphokinase (CK-MB), and I-isoform of troponin (Trop-I) were serially measured (Figure 2). On day 1, the level of CK-MB was $43 \mathrm{ng} / \mathrm{mL}$ (normal; $<5 \mathrm{ng} / \mathrm{mL}$ ), which had increased to $2,927 \mathrm{ng} / \mathrm{mL}$ on day 4 . The level of Trop-I was $21.8 \mathrm{ng} / \mathrm{mL}$ (normal; $<0.5 \mathrm{ng} / \mathrm{mL}$ ) on day 1 , and had increased to 86.1 $\mathrm{ng} / \mathrm{mL}$ on day 2 . Both levels declined rapidly after reaching their peaks, which were paralleled with ECG changes. The echocardiogram findings on day 7 showed normal wall motion with an $80 \%$ ejection fraction without any segmental hypokinesis. Since the patient was still under controlled ventilation and the liver and kidney dysfunction persisted, neither a coronary angiogram nor venticulography or myocardial scintigraphy was performed.

The patient had been treated with CHDF, intravenous administration of antibiotics, and parenteral nutrition. On day 7, CHDF was terminated, and HDF was undertaken 3 times a week. On day 14, the ECG continued to be normal without a $\mathrm{Q}$ wave. The CK-MB and Trop-I levels were $42.3 \mathrm{ng} / \mathrm{mL}$ and $0.48 \mathrm{ng} / \mathrm{mL}$, respectively. The total serum CPK level was decreased to 1,033 IU/L and his consciousness level returned to normal with a full score of GCS on day 21. Although the patient was still under regular HDF, his renal function was restored and his urine output was $1,200 \mathrm{~mL} /$ day on day 23 . The patient was under rehabilitation on day 21. Since his renal and hepatic functions were improved, on day 25 his family requested that he be transferred to a hospital in his hometown, mainly for the purpose of rehabilitation. Although he had been well for a couple of days in 


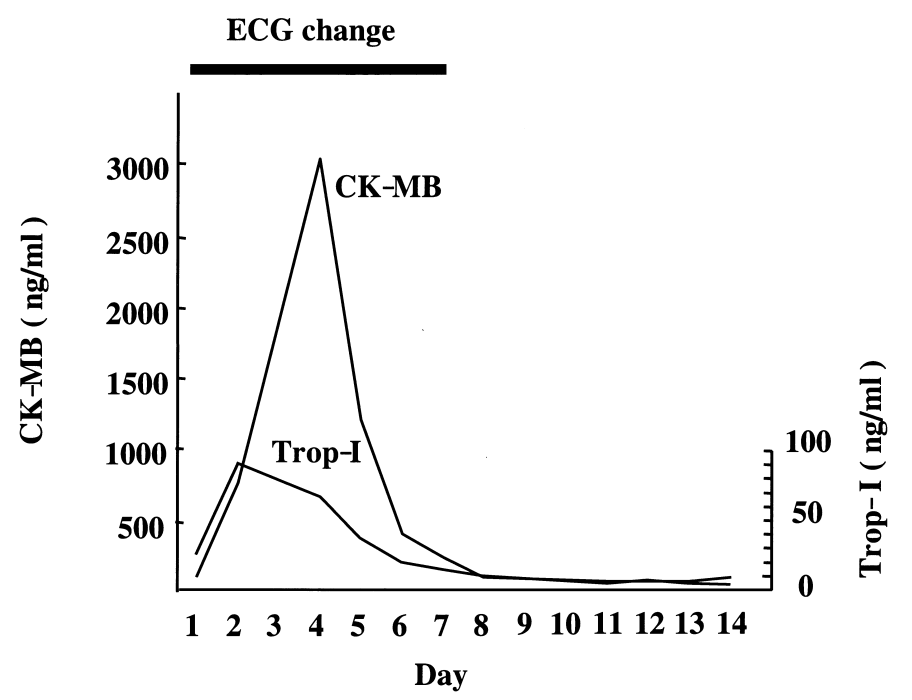

Figure 2. Changes in serum value of myocardial specific markers in severe heat stroke Serum levels of the MB-isoform of creatine phosphokinase (MB-CK) and I-isoform of troponin (Trop-I) were measured serially. The period when the ECG changes were observed is also indicated with a solid bar. MB-CK increased from $43 \mathrm{ng} / \mathrm{mL}$ up to a peak of $2927 \mathrm{ng} / \mathrm{mL}$ (nor$\mathrm{mal} ;>5 \mathrm{ng} / \mathrm{mL}$ ) on day 4 , while Trop-I increased from $21.8 \mathrm{ng} / \mathrm{mL}$ up to $86.1 \mathrm{ng} / \mathrm{mL}$ (normal; $>0.5 \mathrm{ng} / \mathrm{mL}$ ) on day 2 . Both levels declined rapidly after reaching their peaks, which paralleled the ECG changes.

that hospital, his condition worsened on August $4^{\text {th }}$ due to an infection from the central venous catheter. He died on August $6^{\text {th }}$ due to severe sepsis.

\section{Discussion}

This severe heat stroke case was complicated by rhabdomyolysis, acute renal and hepatic failure, and DIC. We used cold blankets and extracorporeal circulation to rapidly reduce his temperature. With the help of CHDF, we successfully controlled his body temperature and mineral balance, and continuously eliminated toxic substances from his body, such as myoglobin, uric acid, and ammonium.

Among his several complications, the cardiac dysfunction was closely monitored and the serial changes in the ECGs were documented. ECG abnormalities and cardiac dysfunction in heat stroke have been reported before. Kew, et al documented 26 heat stroke patients with abnormal ECG in which they found prolonged Q-T intervals, ST-T changes, and T-wave abnormalities. They also reported 2 patients with ST elevation with changes localized to a territory of the 
coronary artery. Other reports have described abnormal ECG findings, which included sinus tachycardia, a conduction defect, a prolonged Q-T interval, diffuse ST-T changes, and ST-T changes localized in a territory of the coronary artery. The prompt normalization of diffuse ST-T depression suggesting transient myocardial ischemia has been reported, and the increased oxygen demand due to high fever, tachycardia, and a significantly high cardiac output state, or hypotension, were considered to be causative factors in this abnormality. ${ }^{6}$ Segmental ST-T elevation has also been reported in severe heat stroke cases. Garcia-Rubira, et al reported a 33-year-old victim of heat exhaustion who suffered from chest pain and whose ECG revealed new Q waves, suggesting myocardial infarction of the inferior wall. ${ }^{7)}$ Nevertheless, diffuse ST elevation in heat stroke unrelated to a territory of the coronary artery and that recovered without $\mathrm{Q}$ wave formation has not been reported.

The etiology of this diffuse ST-T elevation should be discussed. One factor that should be considered is diffuse coronary vasospasm induced by coronary endothelial damage. Bouchama, et al reported the elevation of the plasma concentration of circulating endothelin, intercellular adhesion molecule-1, and von Willebrand factor in 22 precooling heat stroke patients, which implied endothelial cell damage in these patients. ${ }^{9,10)}$ The pathophysiology of myocardial infarction due to coronary vasospasm is in part coronary endothelial dysfunction. ${ }^{11)}$ Although we did not measure these indicators during the treatment of our patient, the ensuing DIC was highly suggestive of diffuse endothelial damage, including in the coronary arteries which might cause coronary vasospasm.

The state of so-called Tako-Tsubo cardiomyopathy is another possible causative mechanism. This disease entity is characterized by transient left ventricular dysfunction with chest symptoms and ECG changes similar to those of AMI but is associated with normal findings on coronary angiography. ${ }^{12)}$ This disease is often misdiagnosed as $\mathrm{AMI}^{13)}$ and is usually accompanied by preceding psychological stress or pre-existing clinical conditions, such as a subarachnoidal hemorrhage, ${ }^{14)}$ pheochromocytoma, ${ }^{15)}$ and syndrome malin. ${ }^{16)}$ Recently, Ogura, et al compared ECG findings between Tako-Tsubo cardiomyopathy and AMI, and reported that the longer QTc interval and the absence of abnormal Q waves in the anterior leads and reciprocal changes in the inferior leads could help to distinguish Tako-Tsubo cardiomyopathy from AMI. ${ }^{17)}$ Although a definite diagnosis by coronary angiography was lacking in this case, considering similar ECG findings, easy reversibility of cardiac function, and the pre-existing stressful condition of exposure to high ambient temperature, the cardiac abnormality probably resembled the state of Tako-Tsubo cardiomyopathy. The prominent impaired wall motion in the apex region observed when he was transferred to the emergency room may reflect the typical abnormalities seen in Tako-Tsubo cardiomyopathy. 
The etiology of Tako-Tsubo cardiomyopathy has not yet been elucidated, but stunned myocardium from multiple coronary spasms and direct myocardial toxicity by catecholamines have been suggested. Although we did not measure the circulating levels of catecholamines, the sympatho-adrenal system is reported to be activated in patients with heat stroke. ${ }^{18)}$ Therefore, it is possible that activation of the sympathetic nerve system may have caused the cardiac abnormalities in this case.

We documented the serial changes in several myocardial specific marker levels, which indicated severe damage to the myocardium by heat attack. In parallel to the ECG change and the echocardiographic findings, their levels declined after successful cooling. The follow-up of serum myocardial markers in heat stroke has been reported. Kew, et al analyzed the isozyme of LDH and found that $69 \%$ of heat stroke patients showed elevated LDH levels whose isozyme patterns were indicative of a myocardial origin. ${ }^{5}$ On the other hand, Costrini, et al did not find elevated levels of the MB fraction of $\mathrm{CK}$ in any of their 13 heat stroke patients. ${ }^{19)}$ The difference may be attributable to the severity of exposure of the myocardium to a high temperature and/or the severity of myocardial ischemia. Our data showed extraordinarily high levels of these markers; a 580-fold increase for CK-MB and a 170-fold increase for troponin I above the upper normal. Although the decreased renal excretory function modified these values, these data indicated the presence of severe myocardial damage in our case.

In summary, we have described a case of severe heat stroke in which the ECG revealed diffuse ST-T elevation and the echocardiogram proved diffuse hypokinesis. Serum myocardial markers were significantly elevated. These were normalized within several days without any damage to the myocardium. No Q waves were detected after ECG normalization. Proper treatment with cooling, fluid supplementation, and CHDF may help to prevent the prolonged cardiac damage. Diffuse vasospasm and/or catecholamine toxicity in the myocardium could be considered as underlying factors for cardiac complications in heat stroke. When interpreting ST-T elevation in the ECG of a heat stroke patient, it is important to be aware that this change is not always related to a coronary lesion. Caution must be exercised so as to not misdiagnose it as AMI, because, like in this case, cooling may be sufficient treatment.

\section{REFERENCES}

1. Bouchama A, Knochel JP. Heat stroke. N Engl J Med 2002; 346: 1978-88. (Review)

2. Clowes GH Jr, O'Donnell TF Jr. Heat stroke. N Engl J Med 1974; 291: 564-7. (Review)

3. Knochel JP. Environmental heat illness. An eclectic review. Arch Intern Med 1974; 133: 841-64.

4. Shibolet S, Lancaster MC, Danon Y. Heat stroke: a review. Aviat Space Environ Med 1976; 47: 280-301. (Review) 
5. Kew MC, Tucker RB, Bersohn I, Seftel HC. The heart in heatstroke. Am Heart J 1969; 77: 324-35.

6. Akhtar MJ, al-Nozha M, al-Harthi S, Nouh MS. Electrocardiographic abnormalities in patients with heat stroke. Chest 1993; 104: 411-4.

7. Garcia-Rubira JC, Aguilar J, Romero D. Acute myocardial infarction in a young man after heat exhaustion. Int J Cardiol 1995; 47: 297-300.

8. al-Harthi SS, Nouh MS, al-Arfaj H, Oaraquish A, Akhter J, Nouh RM. Non-invasive evaluation of cardiac abnormalities in heat stroke pilgrims. Int J Cardiol 1992; 37: 151-4.

9. Bouchama A, Hammami MM, Haq A, Jackson J, al-Sedairy S. Evidence for endothelial cell activation/injury in heatstroke. Crit Care Med 1996; 24: 1173-8.

10. Giustolisi R, Musso R, Cacciola E, Cacciola RR, Russo M, Petralito A. Abnormal plasma levels of factor VIII/ von Willebrand factor complex in myocardial infarction--expression of acute phase reaction or index of vascular endothelium damage? Thromb Haemost 1984; 51: 408.

11. Kugiyama K, Ohgushi M, Motoyama T, et al. Nitric oxide-mediated flow-dependent dilation is impaired in coronary arteries in patients with coronary spastic angina. J Am Coll Cardiol 1997; 30: 920-6.

12. Dote K, Sato H, Tateishi H, Uchida T, Ishihara M. Myocardial stunning due to simultaneous multivessel coronary spasms: a review of 5 cases. J Cardiol 1991; 21: 203-14. (Japanese)

13. Kurisu S, Sato H, Kawagoe T, et al. Tako-tsubo-like left ventricular dysfunction with ST-segment elevation: a novel cardiac syndrome mimicking acute myocardial infarction. Am Heart J 2002; 143: 448-55.

14. Pollick C, Cujec B, Parker S, Tator C. Left ventricular wall motion abnormalities in subarachnoid hemorrhage: an echocardiographic study. J Am Coll Cardiol 1988; 12: 600-5.

15. Yamanaka O, Yasumasa F, Nakamura T, et al. "Myocardial stunning"-like phenomenon during a crisis of pheochromocytoma. Jpn Circ J 1994; 58: 737-42.

16. Kawabata M, Kubo I, Suzuki K, Terai T, Iwama T, Isobe M. "Tako-Tsubo cardiomyopathy” associated with syndrome malin: reversible left ventricular dysfunction. Circ J 2003; 67: 721-4.

17. Ogura R, Hiasa Y, Takahashi T, et al. Specific findings of the standard 12-lead ECG in patients with 'Takotsubo' cardiomyopathy: comparison with the findings of acute anterior myocardial infarction. Circ J 2003; 67 : 687-90.

18. al-Hadramy MS, Ali F. Catecholamines in heat stroke. Mil Med 1989; 154: 263-4.

19. Costrini AM, Pitt HA, Gustafson AB, Uddin DE. Cardiovascular and metabolic manifestation of heat stroke and severe heat exhaustion. Am J Med 1979; 66: 296-302. 